\title{
Explanation of Five Potential Quality Education Functions in Music Education
}

\author{
Xu Wang \\ Arts Department \\ Henan Institute of Education \\ Zhengzhou, China
}

\begin{abstract}
In recent years, the quantity of students specialized in music in colleges and technical secondary schools are a few times or even a dozen times more than those before reforming and opening up, which is indeed good to the development of art education. However, it becomes a common question before us what will such large quantity of students work on after their graduation. Some students even feel confused with depression. And such thought and mood have influenced and disturbed students' life and study, influencing the overall development of China's music education. The top priorities of music teaching are to understand the role of music education correctly, develop the function of music education positively and enhance students' employability with effects. And the "Five Quality Strengthening Functions" in music education will play an important role in this aspect without doubt, accepting more and more public recognition, and playing an increasingly unique role on the educated ones.
\end{abstract}

Keywords—mu sic education; quality strengthening function

\section{INTRODUCTION}

In recent years, the quantity of students specialized in music in colleges and technical secondary schools are a few times or even a dozen times more than those before reforming and opening up, which is indeed good to the development of art education. However, it becomes a common question before us what will such large quantity of students work on after their graduation.

As we all know, there are few employment opportunities for students specialized in music. And the amount of total current graduates is equal to that of actors in literary and artistic groups nationwide. As a result, students who can stay in literary and artistic groups after graduation are less than $1 \%$, and the other students more than $90 \%$ are facing changing profession or waiting for employment. For this reason, parents and students complain constantly, and some students even feel confused with depression, thinking they have chosen a wrong specialty. As a result, these thoughts and emotions will influence and disturb students' life and study, influencing the overall development of China's music education. So in my opinion, the top priorities of music teaching are to understand the role of music education correctly, develop the function of music education positively and enhance students' employability with effects.
Actually, from a perspective of broad sense, music education is relatively comprehensive not only in the aspects of moral education, aesthetic education and nurture of love, but also undertakes social function in terms of ceremony, environment, physiology and psychology. In my opinion, the strengthening study and development of such functions will help students to find a way out on the one hand, and on the other it will help music institutes to lay good foundation for teaching and walking out of dilemma. In addition, the "Five Quality Strengthening Functions" in music education are accepting more and more social and public recognition in a subtle way, and playing an increasingly unique role on the educated ones. Then, I will describe the "Five Quality Strengthening Functions" with emphas is in detail.

\section{CULTIVATE ST UDENT S' CONSCIOUSNESS AND ABILIT YTO PURSUIT AND CREATE PERFECTION}

To pursuit and create perfection is every music worker's objectives, but also one of the ultimate goals of music education. Therefore, upon music students entered school, teachers began to conduct the elaborate one-to-one guidance in terms of students' skills. Only in this way, can we cultivate outstanding talents and complete the mission of "but God knows, only music worthy of being called the master of human souls and emotions (1)" (Martin Luther).

The students will study and train hard tirelessly until the angelic voice appears. It is told that Confucius once learned to play musical instruments from Shi Xiang, a musician from Lu. Until he had learned it to a certain extent, Shi Xiang said: "You can learn a new one"; yet Confucius said: "No, I just learned the song, and I cannot master the beat accurately." Then, after a period of time, Shi Xiang asked him to learn a new one again, Confucius said" No, I did not grasp the theme of it. " After a period of time, Shi Xiang once again offered to teach him a new one, and Confucius still said "No", because he said he had not have a deep understanding of the author. Thus, Confucius did not learn a new song until he believed he had truly understood the author of the song, King Wen of the Zhou Dynasty. Confucius' attitude towards learning music shows that artistic perfection is the fundamental attribute of music, and striving for perfection is always the music work's duty and objectives.

In fact, a lot of people who learn or even proficient in music are not engaged in music, but gain success in new 
field and became one of the best. Examples such as Confucius and Einstein are not cited here, we will look at the couple of $\mathrm{Li}$ Qiling and $\mathrm{Li}$ Dongming, president of DAWNRA YS PHARMA, a pharmaceutical company listed in Hong Kong. Both of them are graduated in 1960 from Central Conservatory of Music Middle School, and they managed the pharmaceutical factory successfully after changing their profession. When being asked their successful experience, they said with deep feeling that "thanks to music learning, we formed the artistic pursuit of pursuing and creating perfection in the process of learning music nor to forget honor at the sight of money, to make the best drugs with the mind of pursuing angelic voices". This also explains why music students can achieve success after changed profession, that is to say compared with other education, music education has a strong sense of perfection. Such awareness can dominate life and become people's habits to regulate and control human behavior. Doing a job is like playing music, if we start, we shall do well without adulteration and defects.

\section{CUltivate ST UDENT S' SPIRIT OF PERSEVERANCE AND INDOMIT ABLE FIGHT ING IN SKILLS AND TECHNIQUES PRACTICE}

The spirit of perseverance and indomitable fighting in skills and techniques training is the only one "shortcut" to achieve the stated objectives. There is a saying in China that "we shall learn Suona for period of a year, Sheng for two years, but the voice of Erhu is just like grinding sound even it has been learned for a period of three years". That is to say, it will be cost several years to play a tune of Erhu, and we will unable to play a good or angelic voice if we have no indomitable spirit of learning. A violinist spent two months to practice a short piano piece for perfection. Neighbors were tired of the monotonous melody and went to protest. However, the performer was unwavering until the state of perfection was obtained. Some people say that the process of learning music is a purgatory process, but it is this purgatory makes the musicians and masters.

The aforementioned Mr. Li Dongming sells drugs for other people before he started his own business. He found that a number of pharmaceutical companies will fight for one client, and many pharmaceutical companies have a strong advantage over his own, which puts a lot of pressure on him. However, when others retreated after failing, he was still insisting, even when the opposite party insulted him with feet on the desk, until the opposite party was moved, and he got his first pot of gold. Someone asked what will he rely on to persist? He replied: "Nothing can be relied upon, just the spirit of learning music." Apparently, the spirit of facing the difficulties to learn has been profoundly etched in the mind of music learners. So after a lot of people have walked out of this profession, the spirit of fighting is still exist, and plays out in working process from passive to active, from active to the automatic.

\section{CULTIVATE STUDENT S' SPIRIT OF PRECISENESS AND LONELINESS ENDURANCE IN PRACTICE}

We often see the musicians gain a lot of applause with fame in the process of performing, but we cannot see their lonely and hard practice, which is a living and learning state that a music student must be accustomed to. In the 1960s, Zhu Zhu from the Central Conservatory of Music Middle School started to learn piano when she is three years old. And in order to prevent her to escape, her parents tied her feet on the pedal. And for fear of her loneliness, her father bought a bird and hung it above the piano to accompany her. At such a young age, Zhu Zhu knew that the poor bird lost freedom like her, then she opened the cage and released the bird, leaving herself to practice piano hard in loneliness. So for children learners, loneliness is the enemy when they started to learn music. The boring, loneliness and mechanization while practicing make so many learners feel pain, but they have to practice note by note and song by song, as making up a number without active work is not feasible here. Everyone must learn to mold himself/herself in loneliness to obtain self-improvement. It can be said that loneliness endurance is a survival instinct for music students, which may enable them to conquer new musical peak, and can also make them calm in loneliness or in a noising environment to cope with difficulties unhurriedly, and make them restrain themselves from seeking quick success and instant benefits as well as from pursuing of superficial lu xury, so as to ponder and make progress in loneliness to obtain a more perfect career. Cao Guilin, the author of TV play "A Native Of Beijing In New York" graduate from Central Conservatory of Music Middle School in 1967, started his experience in the United States from the loneliness and washing dishes, and his endurance of loneliness won him a new life .

Of course, students shall also learn to do music elaborately which is the key to a successful profession or business.

\section{CUltivate ST UDENT S' HABIT OF OBEYING ORDERS WIT HOUT DEVIATION FROM MUSIC BOOK DURING THE SHOW.}

Reading music book and watching commander is the basic skills a beginner shall master, but also the principles that a musician shall follow lifelong after he or she took to the stage. The purpose of reading music book is to song or play the music in accordance with the book, so that the song will not deviate from the book, to make harmony and deviation unify within voices; and watching command refers to the guarantee for the band to be a unity with appropriate speed and strength. However, the cultivation of students' habit and awareness to obey command is a slow education process.

From disobedience to obedience is the common process for general music work to transfer to a musician. Most children who learn music tend to be proud. Obedience and freedom have always been a contradiction, and rebelliousness is an intrinsic property of people. Music education starts from small things in accordance with the 
requirements of perfect expression of music, to educate students from rebellious to conscious, fromblind to the unity of purpose, and allow students to seek with effort the best combination between themselves with musical works and command in accordance with the requirements of music book and command, to make the show perfect.

To obey command without deviation from music book is the basic homework a music worker shall do to play or sing well. And as time progresses, this habit of obeying command will go deep in the music worker's mind. Similarly, such a sense of obedience will deeply affect their thinking and behavior, making them to be honesty and punctuality in daily life; as long as there is a requirement in work, they will try to accomplish.

Such sense of obedience has been transformed into the character of many music students who have changed their profession consciously or unconsciously, and help them find this new "score" of obeying the development rules of things. They select the target according to their own characteristics and development rules of things, to determine what they can do and what shall not do. Then to select routes follow the development rules of things, once the target is determined, they will do it firmly. For example, Einstein's scientific discoveries are all obtained through following the development rules of things. Science lays priority emphasis on existence and can be confirmed. People follow the development rules of things to discover, understand and use it, making it better serve human, this is science. Again, the aforementioned Li Dongming, got his first pot of gold after changing his profession by according to the characteristics of human, and doing things in accordance with the development rules of things. Later even he himself was surprised. In fact, the internal factors of his success is the awareness of obeying command without deviation brought by music education.

To make one thing successfully, there are a lot of constraints, such as market regulations, price, quality, internal and external factors, etc., all linking with one another, with no segment can be missed. Things have there own law of development no matter how many constraints there are, and we will achieve success without opportunistic and dishonest thought, and do things uns wervingly according to the laws. Everyone who has received music education in this area has a bit professional advantage, as it is not selftaught. Music education contains it all the way, but teachers seldom tell students to use this view to guide life, or tell them to learn obedience, which is the essence of good music and successful human conduct while teaching students to watch music book and obey the command.

\section{CUltivate ST UDENT S' COOPERATIVE AWARENESS AND TEAM SPIRIT DURINGTHE SHOW}

In addition to the above four potential, compared with other disciplines, music education is also relatively prominent in cultivation of students, strong sense of cooperation and teamwork. For most musical works, they not only show the skills, but also a spirit of cooperation. If there is only the superb skill without a seamless collaboration, then even the best piece of music cannot show its effect.
Overall concept and cooperative awareness has long been the basic guarantee for musicians to do music well. And it is also another guarantee for music students to successfully transfer to other sectors. As everyone knows the importance of cooperation, so exclusiveness will not be produced after they changed their profession, but they will better work together with team me mbers, and seek common development. This eliminates unnecessary interference, showing the individual's character charm, so as to achieve a win-win result.

There are so many quality strengthening functions in music education, then why the students can not properly fulfill their role in employment? I think there are five areas needing attention and shall to be strengthened.

- Improve the understanding of music education in strengthening individual capabilities. Currently, although the potential of potential quality function in music education is strong, people don't study it by regarding it as a subject, but treat it as a requirements in professional art education, which will undoubtedly weaken its function. If music institutions can conduct their specialized research in it, then the essence of this potential will not only be the ladder to success for students to further study, but also the powerful guarantee to cultivate students' charisma and to help them achieve success in life.

- Establish specialized courses and bring potential quality education into classroom. Potential quality education shall be conducted from two as pects, first is to integrate it into current professional skills education and cultivate students' potential spirit in skills practices; the second is to teach students about the potential function, cultivation and application, and to transfer later discernment to clear beforehand.

- Invite successful graduates back to school to give lectures that focus on the relationship between the function of music to strengthen potential quality and success, to show the generation and role of potential function and the feeling after potential has been given play successfully with examples, enabling the majority of students to strengthen their understanding of quality potential in music education through examples, thus learn how to correctly use this potential.

- Take initiative to organize students to participate in social practice and experience the application of strengthening quality functions on them. Schools shall organize students to do some activities that are good for giving play to strengthening potential quality function during holidays or in their spare time while students are learning professional skills. Make the approach of strengthening potential quality to be deepened in practice, and to better recognize their own quality strengthening in practice.

- Schools should highlight the potential quality of music students in student employment recommendation, to cause all circles to recognize 
music students. Currently, in addition to arts organizations and some schools have a demand for music students, many industries are not open to music students, as there is an incorrect understanding that music students can do nothing except music. Therefore schools shall make effects to publicize students' potential, so that all sectors of society have a more objective understanding of the students, and give them broad employ ment prospects .

In short, it is expected that through the study and application of "five quality strengthening functions" of music, the majority of music students can draw more energy therefrom and become the talents who may make more contributions to the society.

\section{REFERENCES}

[1] Xie Jiaxin, Research Overview of Chinese Contemporary Music Education, Journal of Nanjing Art Institute (Music \& Performance), 2005, Vol. 3

[2] Fang Yi, Realistic Thinking Connecting History and FutureOverview of "Chinese Contemporary Music Research Forum, Journal of Nanjing Art Institute (Music \& Performance), 2005, Vol. 01 